\title{
EDITORIAL
}

\section{Hypertension Guidelines: The 2014 Joint National Committee 8 vs All the Rest. We Can do Better}

\author{
K. Kaitanidis ${ }^{1}$, M. Doumas ${ }^{1,2}$, K. Tziomalos ${ }^{3}$ and V.G. Athyros ${ }^{1, *}$ \\ ${ }^{I}$ Second Propedeutic Department of Internal Medicine, Medical School, Aristotle University of Thessaloniki, \\ Hippocration Hospital, Thessaloniki, Greece; ${ }^{2}$ Veteran Affairs Medical Center and George Washington University, \\ Washington, DC, USA; ${ }^{3}$ First Propedeutic Department of Internal Medicine, Medical School, Aristotle University of \\ Thessaloniki, AHEPA Hospital, Thessaloniki, Greece
}

Recent data suggest that there are 36 million people in US with uncontrolled hypertension (HTN). From these, nearly three out of four visited a healthcare professional at least twice in the prior year, $89 \%$ have a usual source of healthcare, and $85 \%$ have some form of insurance [1]. These data suggest that blood pressure (BP) control is not satisfactory in the US. The JNC 6 guidelines were issued in 1997, the JNC 7 in 2003, and we were in the need for new guidance, the $\mathrm{JNC} 8$, that was finally issued in 2014 [2], 11 years after the JNC 7 [3].

In comparison with the previous guidelines, the JNC 8 guidelines are less comprehensive [3] and focus on answering 3 highly-ranked questions [2].

A. Does initiating antihypertensive therapy at specific BP thresholds improve health outcomes?

B. Does treatment with antihypertensive agents to a specified BP goal lead to improved health outcomes?

C. Do various antihypertensive drugs or drug classes differ in benefits and harms regarding specific health outcomes?

The JVC 8 guidelines, in short, addresses BP thresholds at which drug therapy should be initiated, BP targets during treatment, and choice of antihypertensive agents. They recommend [2]:

1. For younger patients (i.e. $<60$ years-old), antihypertensive therapy should be considered when diastolic BP is $\geq 90 \mathrm{mmHg}$ or systolic BP is $\geq 140 \mathrm{mmHg}$. The goal is $<140 / 90 \mathrm{mmHg}$, but only the diastolic BP thresholds are based on high-quality evidence.

2. For older patients (i.e $\geq 60$ years-old), antihypertensive treatment should be considered when diastolic BP is $\geq 90 \mathrm{mmHg}$ or systolic $\mathrm{BP}$ is $\geq 150 \mathrm{~mm} \mathrm{Hg}$; the goal is $<150 / 90 \mathrm{mmHg}$.

3. For patients with diabetes mellitus or chronic kidney disease, the threshold to initiate drug therapy is $140 / 90$ $\mathrm{mmHg}$; the goal is $<140 / 90 \mathrm{mmHg}$.

4. In non-black patients, acceptable initial drug-class choices are thiazide-type diuretics, calcium-channel blockers (CCBs), angiotensin-converting-enzyme (ACE) inhibitors, and angiotensin-receptor blocker (ARBs).

*Address correspondence to this author at the 15 Marmara St, Thessaloniki, 551 32, Greece; Tel: + 302310 892606; Fax + 302310 835955;

E-mails: vathyros@gmail.com and athyros@med.auth.gr
5. In black patients, acceptable initial drug-class choices are thiazide-type diuretics and CCBs.

6. Patients with chronic kidney disease generally should receive ACE inhibitors or ARBs.

7. When patients require escalation of therapy, either maximizing doses of individual drugs consecutively or combining several drugs at submaximal doses is recommended [2].

\section{WHAT HAS CHANGED SINCE JNC 7?}

JNC 7 [3], the previous guidelines, was a comprehensive document that covered not only HTN treatment, but also definitions of HTN, issues of BP measurement, public health perspectives, lifestyle modification and special situations in HTN management [3]. In contrast, JNC 8 focuses entirely on antihypertensive drug treatment [2]. Moreover, recommendations in JNC 7 were based on observational data and on expert opinion, as well as on data from randomized trials [3]. In contrast, recommendations in JNC 8 mostly reflect randomized trial-derived evidence, with clear acknowledgement when a recommendation reflects only expert opinion [2]. Two specific differences between JNC 7 and 8 in regard to treatment are as follows:

> JNC 7 recommended a treatment threshold of 140/90 $\mathrm{mmHg}$ regardless of age, whereas JNC 8 raises the systolic BP threshold for initiating treatment in patients older than 60 years. In addition, JNC 7 recommended a lower treatment threshold $(130 / 80 \mathrm{mmHg})$ for patients with diabetes or chronic kidney disease, whereas JNC 8 does not.

> In JNC 7, thiazide-type diuretics were recommended as initial drug therapy (unless compelling reasons dictated another drug class), with $\mathrm{CCBs}$, ACE inhibitors, ARBs, and beta-blockers as alternatives. In $\mathrm{JNC} 8$, the initial drug choice is broadened to 4 classes for nonblack patients and 2 classes for black patients. Beta-blockers are no longer recommended for initial therapy because they might confer less protection against stroke.

The JNC 8 is an evidence-based guideline but its scope is limited to drug therapy for HTN, even though authors acknowledge that the benefits of lifestyle changes (diet and exercise) cannot be overemphasized [2]. Most recommendations are reasonable; however, these guidelines might frus- 
trate clinicians who are looking for more comprehensive guidance on HTN management. For example, how do we decide whether a patient with labile BP warrants treatment? (i.e. how many BP readings are required? Are office readings sufficient or ambulatory BP measurement should also be used?). Should we use hydrochlorothiazide or chlorthalidone as a diuretic, given that accumulating data suggest that the latter might be more effective in reducing cardiovascular events [4]? For patients with resistant HTN, what is the practical checklist of tests and treatments that we should consider before referring the patient to a hypertension expert [5]?

The American Society of Hypertension (ASH) and the International Society of Hypertension (ISH) released their own guidelines [6] in the same week that the JNC 8 was published. Their guidelines are more comprehensive than JNC 8 and address the questions posed above and many others which are not covered by JNC 8 . Nevertheless, their treatment recommendations are similar to those of JNC 8, with one exception, that they raise the systolic BP treatment threshold to $>150$ $\mathrm{mmHg}$ only in patients older than 80 years [6-8].

What are the implications of changes suggested by the JNC 8 guidelines? There are a lot of changes when new guidelines are issued, whether these are dyslipidemia guidelines [9] or hypertension guidelines [2]. It takes a lot of time for physicians to educate patients and acquaint them with treatment goals. With these new guidelines, targets have changed, and this can create a lot of issues, one being that "Physicians are arguing about BP optimal numbers", according to the printed and electronic press. Educational leaflets and handouts should also change to conform to the new guidelines.

A second problem is that there are goal-attainment issues that affect quality indicators. We have quality indicators for our practices, and if we don't achieve target goals, our quality indicators fall off. The JNC8 guidelines change those numbers. There are also issues for reimbursement. We have reimbursement issues that come up for pay-for-performance patients - contracts that will be affected by these changes [10]. We also have issues that change with electronic records, so the new guidelines would change them as well. However, the most important issue is physician credibility. We are preaching the critical role of low-density lipoprotein cholesterol (LDL-C) lowering, and then it gets changed in an age-driven way - so, don't worry about your LDL-C, we will just give you a potent statin because you turned 60 years-old for cardiovascular prevention [11]. And because you turned 60 years-old there are different goals for HTN now and we can loosen the antihypertensive treatment you are taking for cardiovascular prevention [2]; this creates a lot of confusion.

The American College of Cardiology/American Heart Association (ACC/AHA) has issued a statement that they are not going to recognize JNC 8. So where does that leave us in terms of who we should believe? Do we believe ACC/AHA or the JNC 8 panel? This is a great dispute confusing people and it is not clear where this leaves us. Anyhow we should not forget that "Guidelines are not the truth, they are some- one's interpretation of current evidence". Thus, maybe we were "lost in the translation".

In any case it might be better to follow the European Society of Hypertension/European Society of Cardiology (ESH/ESC) guidelines [8]. These Societies seem to be able to understand each other better and their joint guidelines are more balanced.

\section{CONFLICT OF INTEREST}

The authors confirm that this article content has no conflicts of interest.

\section{ACKNOWLEDGEMENTS}

Declared none.

\section{REFERENCES}

[1] Frieden TR, King SM, Wright JS. Protocol-based treatment of hypertension: a critical step on the pathway to progress. JAMA 2014; 311: 21-2.

[2] James PA, Oparil S, Carter BL, et al. 2014 evidence-based guideline for the management of high blood pressure in adults: report from the panel members appointed to the $8^{\text {th }}$ Joint National Committee (JNC 8). JAMA 2014; 311: 507-20.

[3] Chobanian AV, Bakris GL, Black HR, et al; National Heart, Lung, and Blood Institute Joint National Committee on Prevention, Detection, Evaluation, and Treatment of High Blood Pressure; National High Blood Pressure Education Program Coordinating Committee. The seventh report of the Joint National Committee on Prevention, Detection, Evaluation, and Treatment of High Blood Pressure: the JNC 7 report. JAMA 2003; 289: 2560-72.

[4] Tziomalos K, Athyros VG, Mikhailidis DP, Karagiannis A. Hydrochlorothiazide $v s$. chlorthalidone as the optimal diuretic for the management of hypertension. Curr Pharm Des 2013; 19: 3766-72.

[5] Messerli FH, Chavez P, Bangalore S. $8^{\text {th }}$ joint national committee: evidence vs. eminence. Am J Cardiol 2014; 113: 2086.

[6] Weber MA, Schiffrin EL, White WB, et al. Clinical practice guidelines for the management of hypertension in the community a statement by the American Society of Hypertension and the International Society of Hypertension. J Hypertens 2014; 32: 3-15.

[7] Murthy VL, Shah RV, Rubenfire M, Brook RD. Comparison of the treatment implications of American Society of Hypertension and international society of hypertension 2013 and $8^{\text {th }}$ joint national committee guidelines: an analysis of national health and nutrition examination survey. Hypertension 2014; 64: 275-80.

[8] Weber MA. Recently published hypertension guidelines of the JNC 8 panelists, the American Society of Hypertension/International Society of Hypertension and other major organizations: introduction to a focus issue of the Journal of Clinical Hypertension. J Clin Hypertens (Greenwich) 2014; 16: 241-5.

[9] Stone NJ, Robinson JG, Lichtenstein AH, et al; American College of Cardiology/American Heart Association Task Force on Practice Guidelines. 2013 ACC/AHA guideline on the treatment of blood cholesterol to reduce atherosclerotic cardiovascular risk in adults: a report of the American College of Cardiology/American Heart Association task force on practice guidelines. J Am Coll Cardiol 2014; 63: 2889-934

[10] Doumas M, Tziomalos K, Athyros VG. Pay-for-performance vs. a budget-restrictive system for the management of dyslipidemia. should this approach also be applied in hypertension? Open Hypert J 2013; 5: 32-34

[11] Athyros VG, Katsiki N, Karagiannis A, Mikhailidis DP. The 2013 American College of Cardiology/American Heart Association guidelines for the treatment of dyslipidemia: Mind the gaps! Curr Med Res Opin 2014; 30: 1701-5. 